\title{
Amorphous $\mathrm{CoMoS}_{4}$ for a valuable energy storage material candidate
}

Xiaoyang $\mathrm{Xu}^{1}$, Yahui Song ${ }^{1}$, Ruinan $\mathrm{Xue}^{1}$, Jingkuo Zhou ${ }^{1}$, Jianping Gao ${ }^{1,2}$, Fubao Xing $^{1 *}$

${ }^{1}$ Department of Chemistry, School of Science, Tianjin University;

${ }^{2}$ Collaborative Innovation Center of Chemical Science and Engineering (Tianjin), Tianjin 300072, China;

\begin{abstract}
The amorphous $\mathrm{CoMoS}_{4}$ is prepared using a simple precipitation method and for the first time used as a supercapacitor material. Surprisingly, it possesses very good electrochemical behavior owing to its amorphous structure and multiple oxidation states. In a three-electrode system, the ratio capacitance of $\mathrm{CoMoS}_{4}$ sample can reach $661 \mathrm{~F} \mathrm{~g}^{-1}$ at a current density of $1 \mathrm{~A} \mathrm{~g}^{-1}$. In the actual application of $\mathrm{CoMoS}_{4}$, the $\mathrm{CoMoS}_{4}$ symmetric device shows the ratio capacitance of $142 \mathrm{~F} \mathrm{~g}^{-1}$ at $2 \mathrm{~A} \mathrm{~g}^{-1}$; the assembled $\mathrm{CoMoS}_{4} / / \mathrm{rGO}$ hybrid supercapacitor also owns a high ratio capacitance of $68 \mathrm{~F} \mathrm{~g}^{-1}$ at $1 \mathrm{~A} \mathrm{~g}^{-1}$ with energy and power densities of $27.2 \mathrm{Wh} \mathrm{kg}^{-1}$ at $400 \mathrm{~W} \mathrm{~kg}^{-1}$ and $17 \mathrm{Wh} \mathrm{kg}^{-1}$ at $2400 \mathrm{~W} \mathrm{~kg}^{-1}$. Further the hybrid supercapacitor has good capacitance retention ( $86 \%$ after 10000 cycles), low internal and Warburg resistances.
\end{abstract}

Keywords: amorphous; capacitance; hybrid supercapacitor

\section{Introduction}

The ever-growing demand for energy, as well as the tremendous growth of

*Corresponding author: fubaoxing2012@ 163.com $(F$ B Xing) 
consumer electronic devices and hybrid electric vehicles, has greatly stimulated scientists to explore high-performance energy conversion and storage devices [1]. However, the Li-ion batteries and fuel cells alone cannot meet all the requirements of performances and technologies [2]. Therefore, supercapacitors have created a great deal of research interest due to their high energy and power densities, quick charge/discharge process and long cycle longevity [3-5].

The transition metal oxides have been generally regarded as the effective electrode materials on account of their high theoretical capacities, low costs and toxicities [6-7]. Many material like $\mathrm{NiO}$ [8], $\mathrm{CoO} / \mathrm{Co}_{3} \mathrm{O}_{4}$ [9], $\mathrm{MnO}_{2}$ [10] and $\mathrm{MoO}_{3}$ [11] have been reported to exhibit very good supercapacitive properties. Unfortunately, the poor conductivity of these oxides hinders their employment in high-rate capability devices along with rapid electron transport [12]. Surprisingly, the transition metal sulfides have higher conductivities than their corresponding oxides [13]. The transition metal sulfides, such as $\mathrm{NiS} / \mathrm{Ni}_{3} \mathrm{~S}_{2}$ [14-15], $\mathrm{CoS}$ [16] and $\mathrm{MoS}_{2}$ [17] have been widely used in supercapacitors and shown outstanding performances. Moreover, in accordance with binary metal oxides, the binary metal sulfides with their multiple redox reactions tend to have better electrochemical behaviors than single component metal sulfides [18]. However, among the binary metal sulfides, there are few reports about applying other binary metal sulfides in supercapacitors apart from $\mathrm{NiCo}_{2} \mathrm{~S}_{4}$, to our best knowledge. Therefore, the development of some new and high-performance binary metal sulfides as supercapacitive materials is still necessary. The abundance of Co and Mo in nature as well as the high theoretical capacities of $\mathrm{CoS}$ (or $\mathrm{CoO}$ ) and 
$\mathrm{MoS}_{2}$ (or $\mathrm{MoO}_{2}$ ) make $\mathrm{CoMoS}_{4}$ ideal candidates for further investigation. In fact, it has been investigated for using in dye-sensitized solar cells [19] and secondary lithium batteries [20].

In this work, the $\mathrm{CoMoS}_{4}$ sample was prepared using a very easy precipitation method. The $\mathrm{CoMoS}_{4}$ was then characterized by X-ray diffraction (XRD), X-ray fluorescence (XRF), X-ray photoelectron spectroscopy (XPS), scanning electron microscopy (SEM), transmission electron microscopy (TEM), selected area electron diffraction (SAED), energy dispersive spectrometry (EDS), elemental mapping analyses and Raman analysis. Moreover, it is the first time to explore the supercapacitive performances of $\mathrm{CoMoS}_{4}$ to our knowledge. It is well known that the electrochemical properties of an electrode material not only rely on its nature, conductivity and surface area but also on the electrolyte. Since the aqueous electrolyte is low cost, safe, environmentally friendly and has good cycling performance [21], 1 $\mathrm{M} \mathrm{KOH}$ was used as the electrolyte.

The capacitances of the prepared $\mathrm{CoMoS}_{4}$ were determined in a three-electrode setup. In order to better understand the actual properties of $\mathrm{CoMoS}_{4}$, a symmetric device using $\mathrm{CoMoS}_{4}$ as both the positive and negative electrode materials was also studied in a two-electrode cell. Further, a hybrid supercapacitor was assembled with $\mathrm{CoMoS}_{4}$ as the positive electrode and reduced graphene oxide (rGO) as the negative electrode and characterized. Both the rGO and activated carbon are common negative electrode materials in hybrid supercapacitors [22-24]. The $\mathrm{CoMoS}_{4} / / \mathrm{rGO}$ hybrid supercapacitor was investigated to have high energy and power density. 


\section{Experimental}

\subsection{Materials}

$\left(\mathrm{NH}_{4}\right)_{2} \mathrm{MoO}_{4},\left(\mathrm{NH}_{4}\right)_{2} \mathrm{~S}, \mathrm{CoCl}_{2} \cdot 6 \mathrm{H}_{2} \mathrm{O}$ and ethanol were all acquired from Tianjin Jiangtian Chemical Company and used without any further processing.

\subsection{Preparation of $\mathrm{CoMoS}_{4}$}

$\left(\mathrm{NH}_{4}\right)_{2} \mathrm{MoO}_{4}(2.5 \mathrm{~g})$ was placed in a beaker $(150 \mathrm{~mL})$ in a water bath at $70{ }^{\circ} \mathrm{C}$. Then an excess of $\left(\mathrm{NH}_{4}\right)_{2} \mathrm{~S}$ solution was added dropwise with stirring to react with the $\left(\mathrm{NH}_{4}\right)_{2} \mathrm{MoO}_{4}$. The reaction was monitored by observing the UV-vis absorption peak at $396 \mathrm{~nm}$ and when this peak disappeared, the reaction was complete. The mixture was then cooled to a low temperature $\left(\sim 5^{\circ} \mathrm{C}\right)$ to allow the $\left(\mathrm{NH}_{4}\right)_{2} \mathrm{MoS}_{4}$ to crystallize. The $\left(\mathrm{NH}_{4}\right)_{2} \mathrm{MoS}_{4}$ crystals were separated by centrifugation and rinsed with cold ethanol to obtain the product $\left(\mathrm{NH}_{4}\right)_{2} \mathrm{MoS}_{4}$.

The above prepared $\left(\mathrm{NH}_{4}\right)_{2} \mathrm{MoS}_{4}(4 \mathrm{mmol})$ and $\mathrm{CoCl}_{2} \cdot 6 \mathrm{H}_{2} \mathrm{O}(4 \mathrm{mmol})$ were dissolved in a solution of distilled water $(70 \mathrm{~mL})$ and ethanol $(10 \mathrm{~mL})$. The mixture was then stirred at room temperature to yield a $\mathrm{CoMoS}_{4}$ precipitation. The precipitate was collected by centrifugation, washed with distilled water and ethanol, and dried by a freeze-drying process to obtain $\mathrm{CoMoS}_{4}$ powder.

\subsection{Characterization methods}

The UV-vis spectra, XRD patterns, XRF spectra, XPS spectra and SEM images of $\mathrm{CoMoS}_{4}$ were obtained using a UV-vis spectrophotometer (TU-1901), X-ray diffractometer (BDX3300; Cu Ka radiation, voltage: $30 \mathrm{kV}$ and current: $30 \mathrm{~mA}$ ), XRF 
spectrometer (Bruker, S4 Pioneer), XPS spectrometer (PHI1600 ESCA System, Perkin Elmer, US) and a Hitachi Limited S4800 microscope (Japan), respectively. The TEM, SAED, EDS and elemental mapping analyses were performed using a Philips Tecnai G2F20 microscope. Raman analysis was conducted on a DXR Raman spectrometer (US).

Electrochemical measurements, including cyclic voltammetry (CV), galvanostatic charge/discharge (GCD) cycles and electrochemical impedance spectroscopy (EIS), were conducted on a computer controlled workstation (Shanghai Chenhua $\mathrm{CHI}$ 660D) in $1 \mathrm{M} \mathrm{KOH}$ at room temperature. The electrodes were prepared as follows: an homogeneous slurry of the sample, carbon black and polytetrafluoroethylene emulsion (mass fraction $=60 \%$ ) with a mass ratio of 75:15:10 was coated on a piece of clean $\mathrm{Ni}$ foam $(1 \mathrm{~cm} \times 1 \mathrm{~cm})$. The coated $\mathrm{Ni}$ foam was then dried and pressed to obtain an electrode pad.

The performance of $\mathrm{CoMoS}_{4}$ was investigated with CV and GCD measurements in a three-electrode system, including the prepared $\mathrm{CoMoS}_{4}$ electrode as the working electrode, a piece of $\mathrm{Pt}$ foil with a large-area as the counter electrode and $\mathrm{HgO} / \mathrm{Hg}$ as the reference electrode. A CoMoS 4 symmetric device was studied by CV and GCD. This device constructed using two $\mathrm{CoMoS}_{4}$ electrodes as the positive and negative electrodes and the electrodes were separated using a porous separator. A $\mathrm{CoMoS}_{4} / / \mathrm{rGO}$ hybrid supercapacitor was assembled using the $\mathrm{CoMoS}_{4}$ and $\mathrm{rGO}$ electrodes as the positive and negative electrodes respectively. The hybrid supercapacitor was investigated using CV, GCD and EIS. The EIS measurement was 
conducted in the frequency range from $10 \mathrm{mHz}$ to $100 \mathrm{kHz}$ with a potential amplitude of $5 \mathrm{mV}$ at open circuit potential.

The ratio capacitances of the electrode material $\left(\mathrm{Cs}, \mathrm{F} \mathrm{g}^{-1}\right)$, the symmetric device $\left(\mathrm{Cs}(d), \mathrm{F} \mathrm{g}^{-1}\right)$ and the hybrid supercapacitor $\left(\mathrm{Cs}(h s d), \mathrm{F} \mathrm{g}^{-1}\right)$, the energy density (E, $\mathrm{Wh} \mathrm{kg}^{-1}$ ) and power density $\left(\mathrm{P}, \mathrm{W} \mathrm{kg}^{-1}\right)$ of the hybrid supercapacitor were determined according to the following equations (1-5) [25-26]:

$$
\begin{gathered}
C s=\frac{i \times \Delta t}{\Delta v \times m} \\
C s(d)=\frac{i \times \Delta t}{\Delta v \times M^{\prime}} \\
C s(h s d)=\frac{i \times \Delta t}{\Delta v \times M} \\
E=\frac{1000}{2 \times 3600} C s(h s d)(\Delta v)^{2} \\
P=\frac{3600 \times E}{\Delta t}
\end{gathered}
$$

Where $\mathrm{i}$ is the applied constant current (A), $\Delta \mathrm{t}$ is discharge time (s), $\Delta \mathrm{v}$ is the potential window (V) and $\mathrm{m}, \mathrm{M}^{\prime}$ and $\mathrm{M}$ represent the mass $(\mathrm{g})$ of the active materials in the single electrode, in the two $\mathrm{CoMoS}_{4}$ electrodes in the symmetric device (g) and in the $\mathrm{CoMoS}_{4}$ and rGO electrodes of the hybrid supercapacitor, respectively.

\section{Results and discussion}

When the $\left(\mathrm{NH}_{4}\right)_{2} \mathrm{~S}$ solution was added to $\left(\mathrm{NH}_{4}\right)_{2} \mathrm{MoO}_{4}$, the solution color immediately turned to orange due to the formation of $\mathrm{MoO}_{3} \mathrm{~S}_{2}{ }^{2-}$, and then the solution gradually turned to red as $\mathrm{MoS}_{4}{ }^{2-}$ was formed. The formation of the $\left(\mathrm{NH}_{4}\right)_{2} \mathrm{MoS}_{4}$ was monitored using UV-vis spectroscopy. Spectra were recorded every $10 \mathrm{~min}$ and the results are shown in Figure 1a. Obviously, the area ratio of absorption peaks at about 
396 and $468 \mathrm{~nm}$ decreased with increasing time. After $20 \mathrm{~min}$, the absorption peak at about $396 \mathrm{~nm}$ fully disappeared, indicating that all the $\left(\mathrm{NH}_{4}\right)_{2} \mathrm{MoO}_{4}$ was transformed to $\left(\mathrm{NH}_{4}\right)_{2} \mathrm{MoS}_{4}$. In order to ensure that the reaction was complete, the reaction time of 40 min was selected.

The composition of the prepared $\left(\mathrm{NH}_{4}\right)_{2} \mathrm{MoS}_{4}$ was also verified by XRD and the patterns is shown in Figure 1b. The typical diffraction peaks at about $14.6^{\circ}, 17.1^{\circ}$, $18.5^{\circ}, 23.5^{\circ}, 25.4^{\circ}, 29.1^{\circ}, 31.5^{\circ}, 40.2^{\circ}, 45.7^{\circ}, 53.1^{\circ}$ can be indexed to the $(011),(120)$, (200), (220), (022), (040), (311), (142), (431) and (360) crystal planes for $\left(\mathrm{NH}_{4}\right)_{2} \mathrm{MoS}_{4}$ (JCPDS: 48-1662) respectively, further confirming successful preparation of $\left(\mathrm{NH}_{4}\right)_{2} \mathrm{MoS}_{4}$. The obtained $\left(\mathrm{NH}_{4}\right)_{2} \mathrm{MoS}_{4}$ reacted with $\mathrm{CoCl}_{2}$ at a molar ratio of 1:1 at room temperature to give $\mathrm{CoMoS}_{4}$. When the $\mathrm{CoCl}_{2}$ solution was added to the $\left(\mathrm{NH}_{4}\right)_{2} \mathrm{MoS}_{4}$ solution, a precipitate was observed immediately, which is attributed to the occurrence of a replacement reaction. The XRD pattern (Figure 1b) proves that the $\mathrm{CoMoS}_{4}$ is believed to be amorphous, which is in accordance with the reported result in the literature [27]. In addition, XRF measurement was used to determine the elemental composition of the $\mathrm{CoMoS}_{4}$ sample. The calculated molar ratio of Co, Mo and $\mathrm{S}$ is 1:1.02:3.80, which is close to the stoichiometric ratio of $\mathrm{CoMoS}_{4}$ 

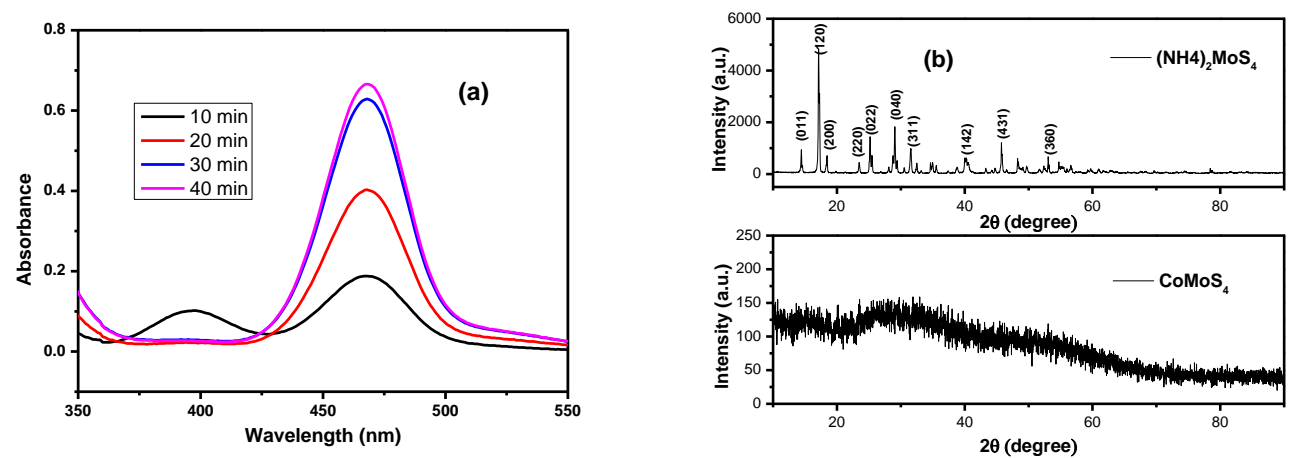

Figure 1.UV-vis spectra taken during the preparation of $\left(\mathrm{NH}_{4}\right)_{2} \mathrm{MoS}_{4}$ (a); XRD patterns of the prepared $\left(\mathrm{NH}_{4}\right)_{2} \mathrm{MoS}_{4}$ and $\mathrm{CoMoS}_{4}$ samples (b)

The chemical composition of the sample can be further verified by XPS analysis and the results are shown in Figure 2. In Figure 2a, the two main peaks located at 797.8 and $779.8 \mathrm{eV}$ in the Co $2 \mathrm{p}$ core level spectrum can be attributed to Co $2 \mathrm{p}_{1 / 2}$ and Co $2 p_{3 / 2}$, which are in consistent with the presence of $\mathrm{Co}^{2+}$. Moreover, the Co $2 \mathrm{p}_{3 / 2}$ binding energy $(779.8 \mathrm{eV})$ is close to that $(779.7 \mathrm{eV})$ for Co-Mo-S reported by Okamoto et al [28], suggesting that $\mathrm{Co}^{2+}$ ions are bonded with $\mathrm{MoS}_{4}{ }^{2-}$. In Figure 2b, the two peaks centered at 235.5 and $232.4 \mathrm{eV}$ correspond to Mo $3 \mathrm{~d}_{5 / 2}$ and Mo $3 \mathrm{~d}_{3 / 2}$, which is in consistent for $\mathrm{Mo}^{6+}$. The peak at $229.0 \mathrm{eV}$ can be assigned to $\mathrm{S} 2 \mathrm{~s}$. The binding energy of $162.9 \mathrm{eV}$ corresponds to $\mathrm{S} 2 \mathrm{p}$ (Figure 2c), which is the characteristic of -2 oxidation state of $S$. These results are consistent with the characteristics of $\mathrm{CoMoS}_{4}$. 

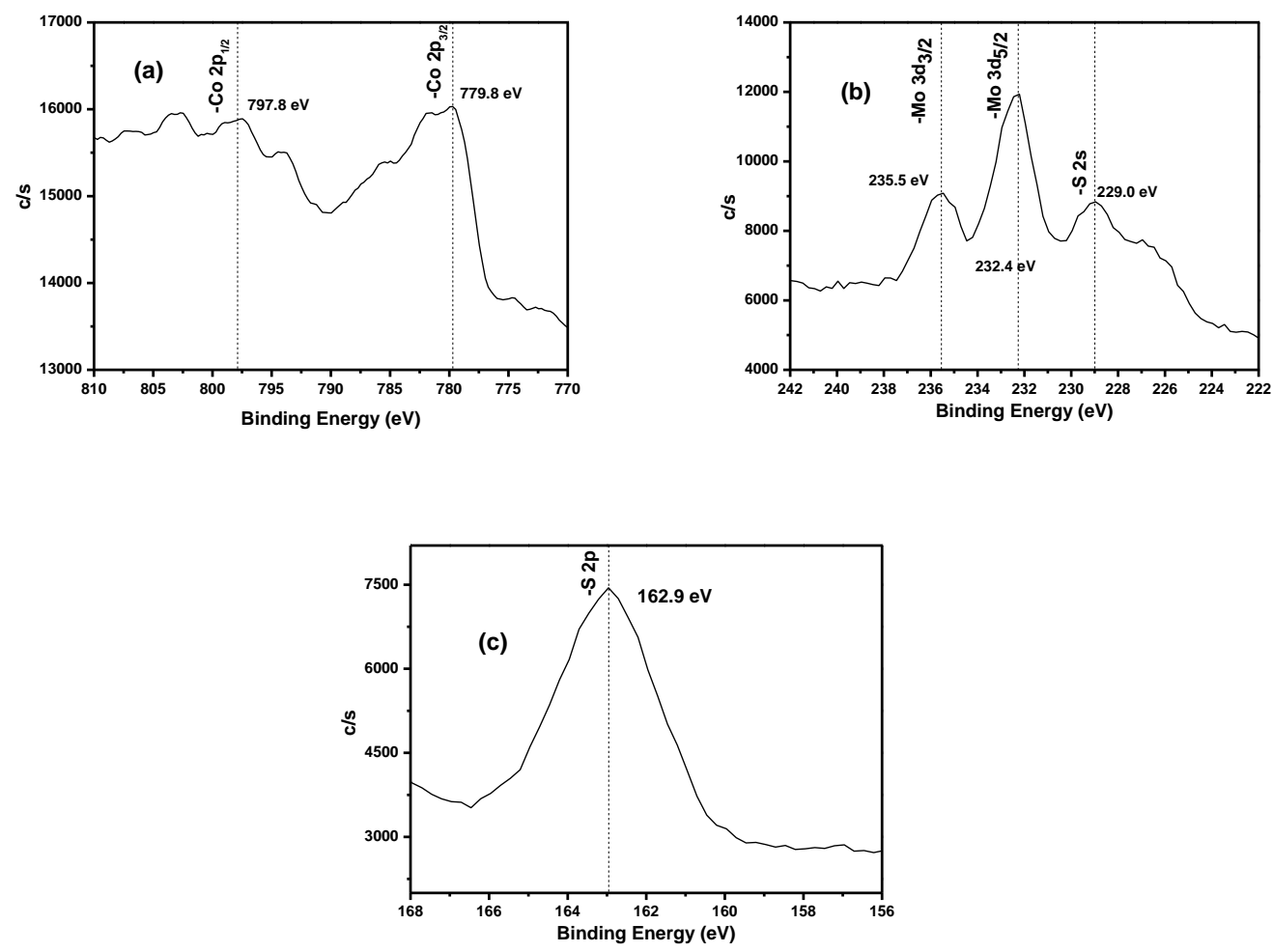

Figure 2. Co 2p (a), Mo 3d (b) and S 2p (c) core level spectra of $\mathrm{CoMoS}_{4}$

The morphology and structure of $\mathrm{CoMoS}_{4}$ can be observed by SEM and TEM images. Many particles and pores are observed in the SEM images at different magnifications (Figure 3a and b). In the TEM images (Figure 3c-d), there are some nano-flakes. It can be concluded that the $\mathrm{CoMoS}_{4}$ particles are composed of many nano-flakes. The flake-like and porous structures often hold large surface area, which can improve the contact area between active materials and electrolyte, leading to high capacitance value. The high-resolution TEM photo of $\mathrm{CoMoS}_{4}$ does not show any diffraction fringes (Figure 3e). Moreover, there is no obvious diffraction rings in the SAED pattern of $\mathrm{CoMoS}_{4}$ (Figure 3f). These results further indicate that $\mathrm{CoMoS}_{4}$ is amorphous. 

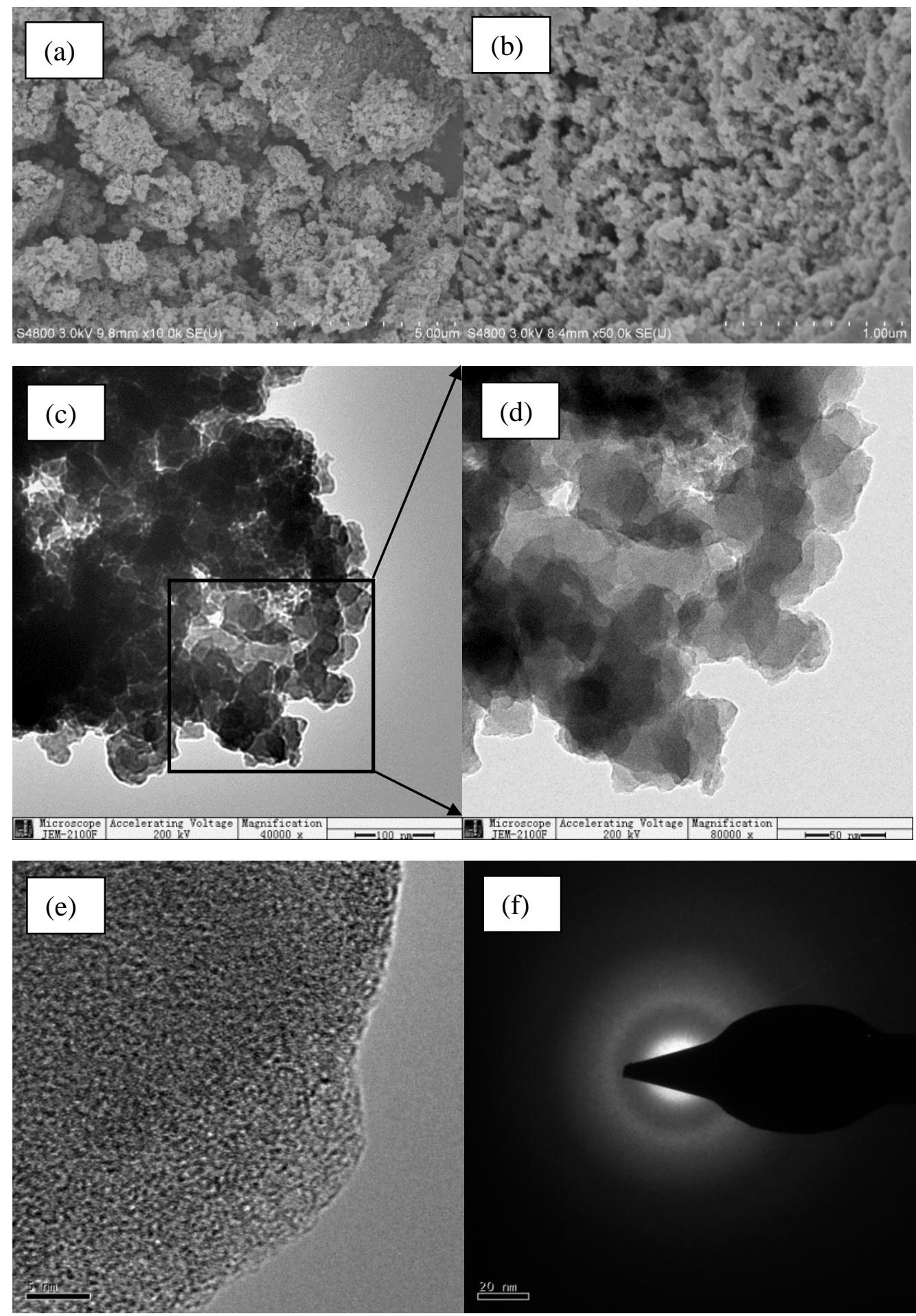

Figure 3. SEM (a-b, scale: $5 \mu \mathrm{m}(\mathrm{a}), 1 \mu \mathrm{m}(\mathrm{b}))$, TEM (c-e, scale: $100 \mathrm{~nm}(\mathrm{c}), 50 \mathrm{~nm}$ (d), $5 \mathrm{~nm}(\mathrm{e})$ ) and SAED (f, scale: $20 \mathrm{~nm}$ ) images of $\mathrm{CoMoS}_{4}$

The EDS analysis was also performed to determine the elements in the $\mathrm{CoMoS}_{4}$ 
sample and shown in Figure 4a. Four elements $\mathrm{Co}$, Mo, $\mathrm{S}$ and $\mathrm{Cu}$ were found. The $\mathrm{Cu}$ element is from the $\mathrm{Cu}$ grid used in the TEM measurement. The Co, Mo and $\mathrm{S}$ elements originate in $\mathrm{CoMoS}_{4}$ and their molar ratio is also close to the stoichiometric proportion of $\mathrm{CoMoS}_{4}$. In addition, to intuitively observe the elemental distribution, the elemental mapping of $\mathrm{CoMoS}_{4}$ was shown in Figure 4b. Obviously, the Co, Mo and $\mathrm{S}$ elements are uniformly distributed throughout the $\mathrm{CoMoS}_{4}$ sample.

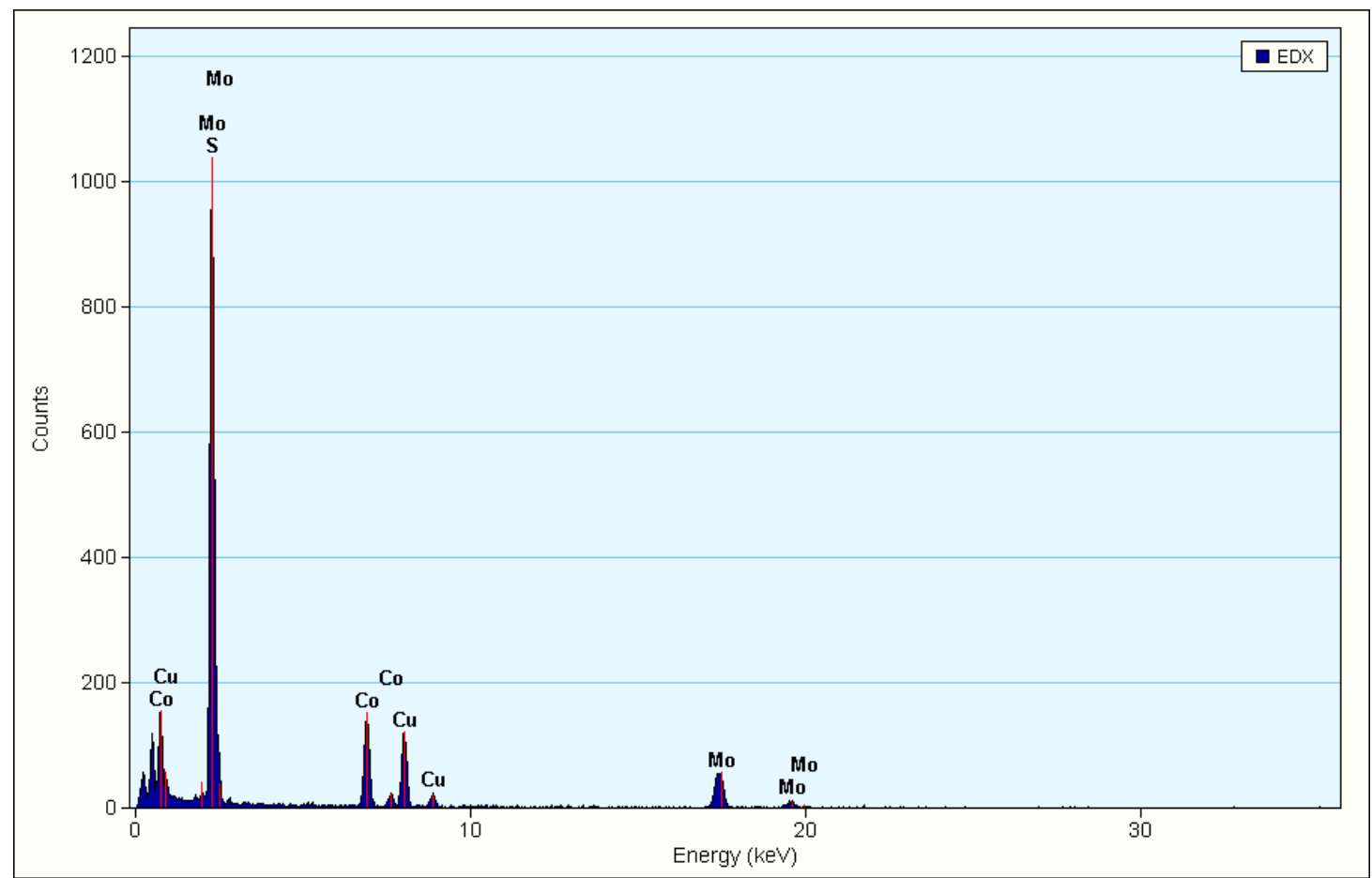

(a) 

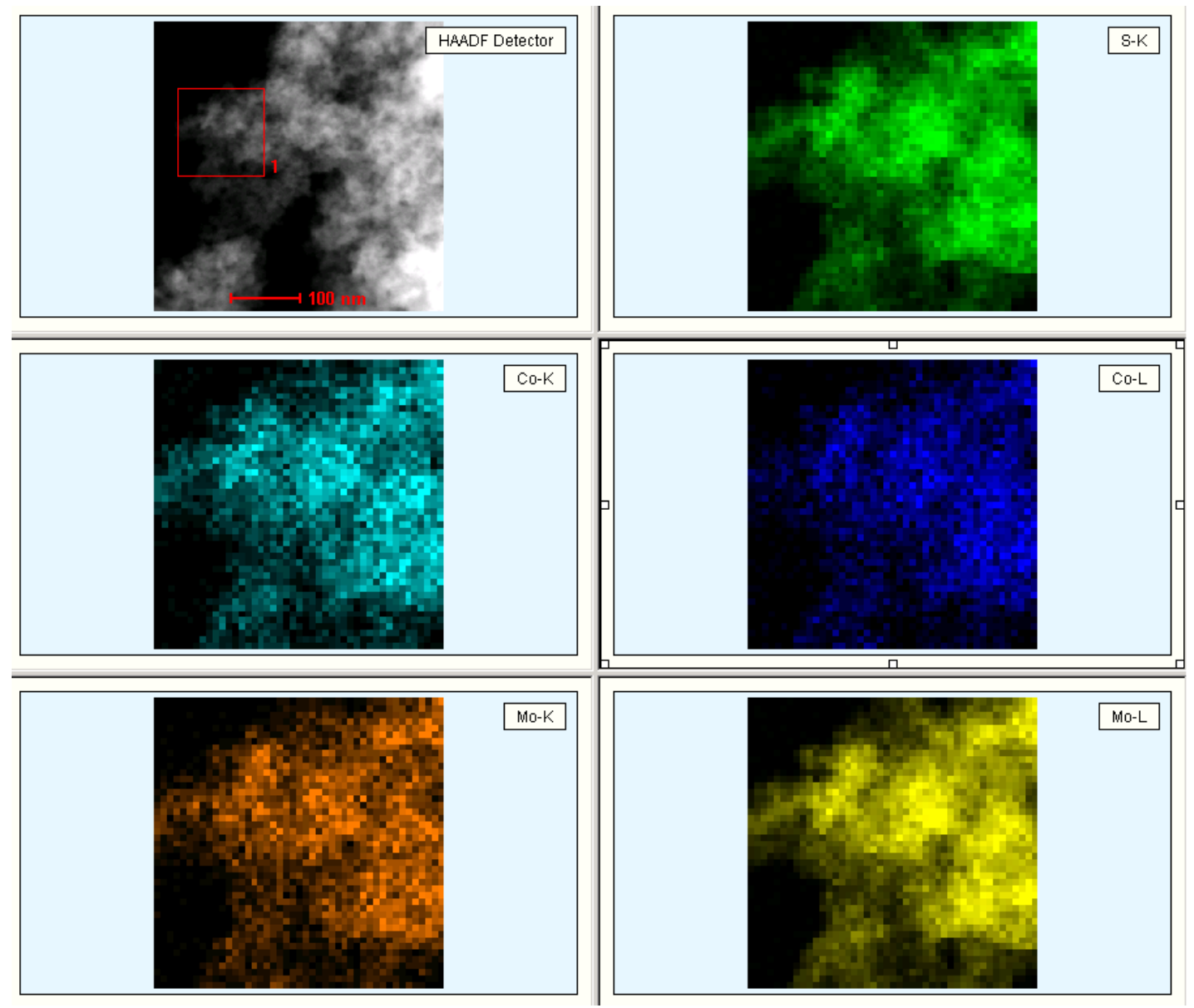

(b)

Figure 4. EDS spectrum (a) and Elemental mapping (b) of $\mathrm{CoMoS}_{4}$

Raman analysis can provide the accurate data about variations in chemical bond distances as well as mechanical behaviors (strain, stress, etc.). Moreover, it is suitable for a variety of materials on account of the effectiveness and non-destructive feature. Figure 5 shows the Raman spectrum of the obtained $\mathrm{CoMoS}_{4}$. The band at $932 \mathrm{~cm}^{-1}$ is associated with the Mo-S symmetric stretching mode. The band located at 858 and $812 \mathrm{~cm}^{-1}$ correspond to $\mathrm{S}$ asymmetric stretching mode in S-Mo-S bond. The band at $366 \mathrm{~cm}^{-1}$ can be attributed to the Co-S-Mo symmetric stretching mode. The band at $404 \mathrm{~cm}^{-1}$ is associated with the out-of-plane vibration of $\mathrm{S}$ atoms in opposite 
directions. In addition, all observed peaks in this spectrum are distinguishing from those of $\mathrm{CoS}_{2}$ [29] and $\mathrm{MoS}_{2}$ [30] in both position and quantity, i.e. the Raman spectrum of $\mathrm{CoMoS}_{4}$ has not any signature of $\mathrm{CoS}_{2}$ and $\mathrm{MoS}_{2}$.

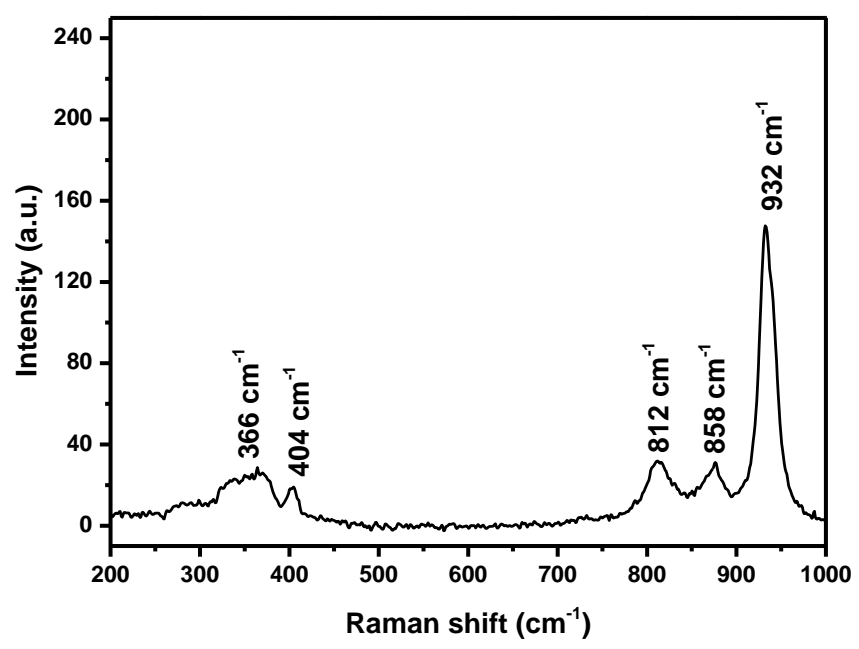

Figure 5. Raman spectrum for $\mathrm{CoMoS}_{4}$

The prepared $\mathrm{CoMoS}_{4}$ should be supposed to use as an electrode material in supercapacitors owing to the amorphous structure and multiple oxidation states [31]. Figure 6a exhibits the $\mathrm{CV}$ curves of $\mathrm{CoMoS}_{4}$ at different scan rates (from 10 to 100 $\mathrm{mV} \mathrm{s}^{-1}$ ) in a potential window of $0-0.7 \mathrm{~V}$. Some redox peaks appear in the CV curves of $\mathrm{CoMoS}_{4}$, indicating that $\mathrm{CoMoS}_{4}$ stores electric energy by a Faradaic redox mechanism [32]. Meanwhile, the oxidation and reduction peaks shift to more positive and negative potentials at a high scan rate, which may be due to the increased inner diffusion resistance in the electrode material [33]. Moreover, the current subsequently increased at higher scan rates but the shape of CV curves is very similar at all scan rates. This fact reflects the good electrochemical capacitance for $\mathrm{CoMoS}_{4}$ [34]. 
The GCD curves (Figure 6b) of $\mathrm{CoMoS}_{4}$ at a potential range from 0 to $0.6 \mathrm{~V}$ were recorded at current densities of 1 to $3 \mathrm{~A} \mathrm{~g}^{-1}$. The nonlinear discharge curves also verify the Faradic nature of $\mathrm{CoMoS}_{4}$. The corresponding charge and discharge curves are nearly symmetric, suggesting the reversible charge/discharge capability of $\mathrm{CoMoS}_{4}$ [35]. The ratio capacitances of $\mathrm{CoMoS}_{4}$ from GCD cycles were calculated according to the equation (1) and are shown in Figure 6c. For current densities of 1, 1.6, 2, 2.4 and $3 \mathrm{~A} \mathrm{~g}^{-1}$, the ratio capacitances of $\mathrm{CoMoS}_{4}$ are 661, 554, 490, 449 and $410 \mathrm{~F} \mathrm{~g}^{-1}$, respectively. Very obviously, the ratio capacitance values are inversely proportional to the scan rates, a common phenomenon. The diffusion time is reduced at a high scan rate, so the electrolyte ions cannot fully access to the inner surface of the active materials for charge storage [36]. The capacitance for $\mathrm{CoMoS}_{4}$ are superior to those of the component sulfides, including $\operatorname{CoS}\left(247.2 \mathrm{~F} \mathrm{~g}^{-1}\right.$ at $1 \mathrm{~A} \mathrm{~g}^{-1}$ [37]), $\mathrm{CoS}_{2}$ (245 $\mathrm{F} \mathrm{g}^{-1}$ at $\left.1 \mathrm{Ag}^{-1}[38]\right)$ and $\mathrm{MoS}_{2}\left(122 \mathrm{~F} \mathrm{~g}^{-1}\right.$ at $0.5 \mathrm{~A} \mathrm{~g}^{-1}$ [39], $142 \mathrm{~F} \mathrm{~g}^{-1}$ at $0.59 \mathrm{~A} \mathrm{~g}^{-1}$ [40], $70 \mathrm{~F} \mathrm{~g}^{-1}$ at $1 \mathrm{~A} \mathrm{~g}^{-1}$ [41]). They are also higher than those of the similar oxides, such as ultrathin nanosheet-assembled $\mathrm{CoMoO}_{4}$ with a mesoporous morphology (135 $\mathrm{F} \mathrm{g}^{-1}$ at $0.6 \mathrm{~A} \mathrm{~g}^{-1}$ ) [42] and hierarchical $\mathrm{MnMoO}_{4} / \mathrm{CoMoO}_{4}$ hetero structured nanowires (187.1 $\mathrm{F} \mathrm{g}^{-1}$ at $\left.1 \mathrm{~A} \mathrm{~g}^{-1}\right)$ [43]. The high capacitance of $\mathrm{CoMoS}_{4}$ may be attributed to the multiple oxidation states, the synergistic effect of $\mathrm{M}$ (Co and Mo) and high conductivity of sulfides [44]. 

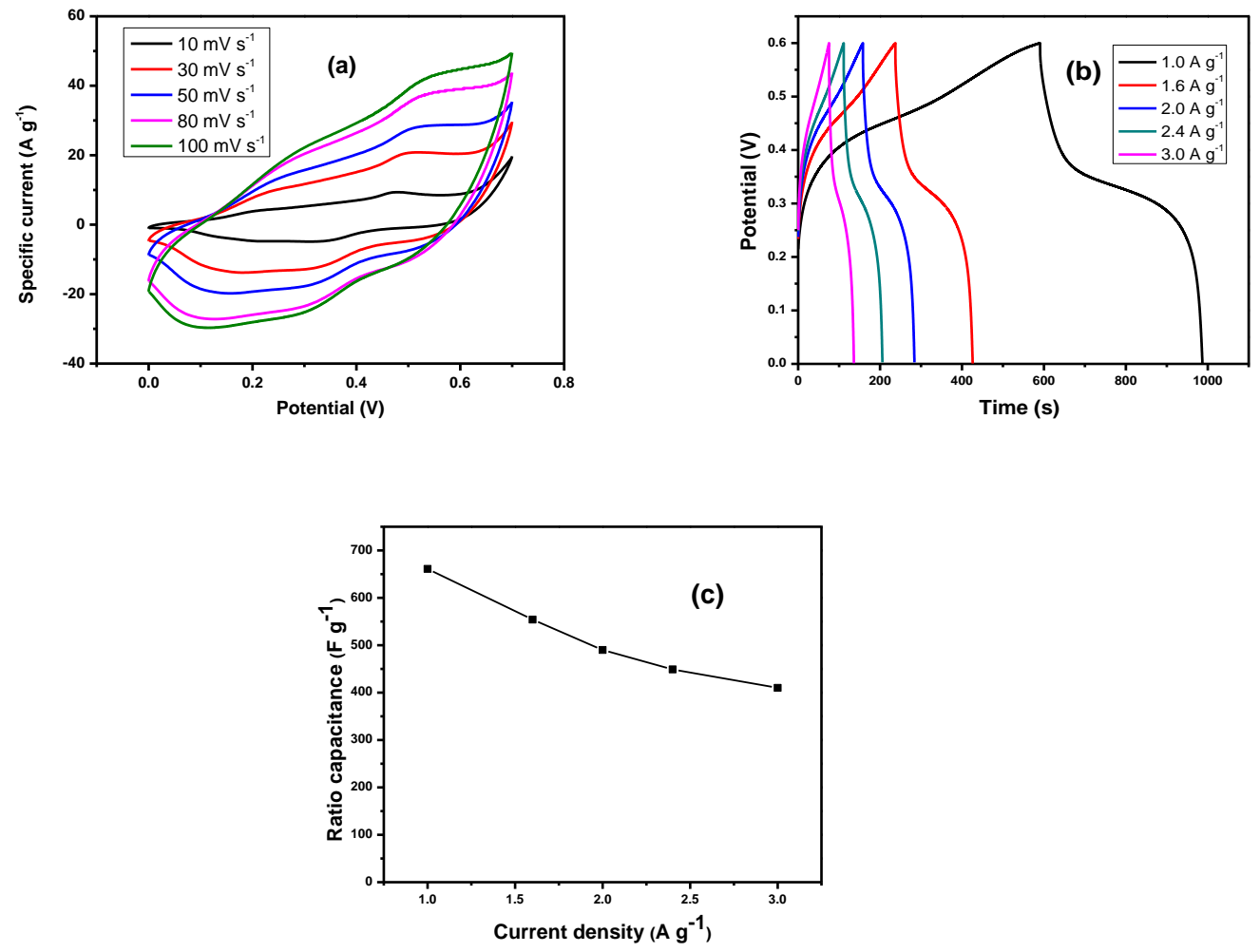

Figure 6. CV curves (a), GCD curves (b) and the corresponding ratio capacitances (c) of $\mathrm{CoMoS}_{4}$ in a three-electrode system

Figure $7 \mathrm{a}$ and $\mathrm{b}$ show the $\mathrm{CV}$ and GCD curves of the $\mathrm{CoMoS}_{4}$ symmetric device at the potential range of $0-1.0 \mathrm{~V}$. In Figure $7 \mathrm{c}$, the ratio capacitances of the symmetric device $\left(\mathrm{Cs}(s d), \mathrm{F} \mathrm{g}^{-1}\right)$ using the equation (2) are 160, 142, 125, 114, 99 and $92 \mathrm{~F} \mathrm{~g}^{-1}$ at 1.8, 2, 2.4, 2.6, 2.8 and $3 \mathrm{~A} \mathrm{~g}^{-1}$ respectively, higher than some other symmetric supercapacitors, such as a UV induced rGO symmetric capacitor $\left(141.2 \mathrm{~F} \mathrm{~g}^{-1}\right.$ at $1 \mathrm{~A}$ $\left.\mathrm{g}^{-1}\right)$ [45], a MoS $2 /$ PANI based symmetric supercapacitor $\left(124 \mathrm{~F} \mathrm{~g}^{-1}\right.$ at $\left.1 \mathrm{~A} \mathrm{~g}^{-1}\right)$ [46] and a $\alpha-\mathrm{MnMoO}_{4}$ symmetric cell $\left(25 \mathrm{~F} \mathrm{~g}^{-1}\right.$ at $\left.1.6 \mathrm{~A} \mathrm{~g}^{-1}\right)$ [47]. 

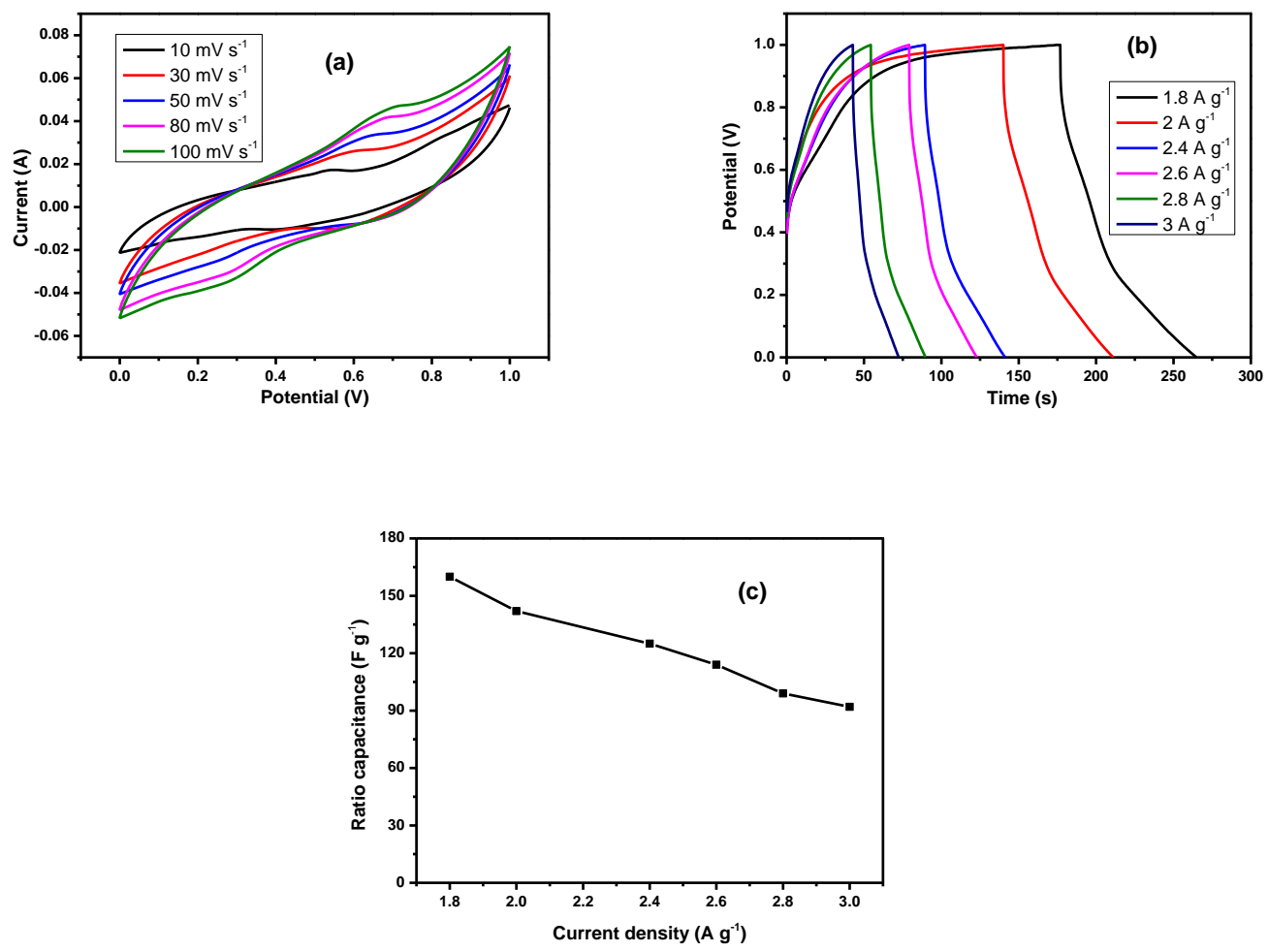

Figure 7. CV curves (a), GCD curves (b) and the corresponding ratio capacitances (c) of the $\mathrm{CoMoS}_{4}$ symmetric device

Figure $8 \mathrm{a}$ exhibits the schematic image of the $\mathrm{CoMoS}_{4} / / \mathrm{rGO}$ hybrid supercapacitor device. The ratio capacitance values of the used rGO in this work are 170, 143, 131, 117, $111 \mathrm{~F} / \mathrm{g}$ at 1, 1.6, 2, 2.6 and $3 \mathrm{~A} / \mathrm{g}$ (Figure 8b). The loading mass of $\mathrm{CoMoS}_{4}$ and rGO are about 3 and $7 \mathrm{mg}$ based on the charge balance, respectively. Figure $8 \mathrm{c}$ and $\mathrm{d}$ show the $\mathrm{CV}$ and GCD curves of the hybrid device in a voltage window of 0-1.6 V. The nearly rectangle $\mathrm{CV}$ and triangle GCD curves confirm the good supercapacitive performance. The ratio capacitances of the $\mathrm{CoMoS}_{4} / / \mathrm{rGO}$ hybrid supercapacitor $\left(\mathrm{Cs}(h s d), \mathrm{F} \mathrm{g}^{-1}\right)$ based on equation (3) are 77, 68, 63, 59, 53 and $48 \mathrm{~F}$ $\mathrm{g}^{-1}$ at $0.5,1,1.5,2,2.5$ and $3 \mathrm{~A} \mathrm{~g}^{-1}$ (Figure 8e), higher than those of other similar hybrid supercapacitors, including $\alpha-\mathrm{MnO}_{2} / \mathrm{MWCNT} / /$ activated carbon $\left(43.3 \mathrm{~F} \mathrm{~g}^{-1}\right.$ at 1 $\left.\mathrm{A} \mathrm{g}^{-1}\right)$ [48] and $\mathrm{rGO} / / \mathrm{CoMoO}_{4}\left(26.16 \mathrm{~F} \mathrm{~g}^{-1}\right.$ at $\left.0.5 \mathrm{~mA} \mathrm{~cm}^{-2}\right)$ [49]. The two key 
parameters $\mathrm{E}$ and $\mathrm{P}$ were determined using the equations (4) and (5). The Ragone plots which relate to $\mathrm{E}$ and $\mathrm{P}$ are exhibited in Figure 8f. The energy density can reach 27.2 $\mathrm{Wh} \mathrm{kg}^{-1}$ at the power density of $400 \mathrm{~W} \mathrm{~kg}^{-1}$, and retains $17 \mathrm{Wh} \mathrm{kg}^{-1}$ at the power density of $2400 \mathrm{~W} \mathrm{~kg}^{-1}$. These values are higher than those of other reported hybrid supercapacitors, such as $\mathrm{ZnO} /$ graphene nanoribbon//lacey reduced graphene oxide nanoribbon (9.4 Wh/kg) [50], CoMn LDH/Ni foam//Activated carbon (4.4 Wh/kg and $2500 \mathrm{~W} / \mathrm{kg})[51]$ and $\mathrm{NiCo}_{2} \mathrm{O}_{4} / \mathrm{NiO} / / \mathrm{Fe}_{2} \mathrm{O}_{3}(19 \mathrm{Wh} / \mathrm{kg}$ and $157 \mathrm{~W} / \mathrm{kg})$ [52].

The stability of a device can be evaluated using capacitance retention. Figure $8 \mathrm{~g}$ indicates the capacitance retention of the $\mathrm{CoMoS}_{4} / / \mathrm{rGO}$ hybrid supercapacitor at 80 $\mathrm{mV} \mathrm{s}^{-1}$. This device retained about $86 \%$ of the initial capacitance after 10000 cycles. This cyclic performance is better than some reported hybrid supercapcitor devices like $\mathrm{MnO}_{2}$ nanowire/graphene//graphene (79\% after 1000 cycles) [53], activated carbon $/ / \mathrm{Co}_{3} \mathrm{O}_{4} @ \mathrm{NiMoO}_{4} \quad(1000$ cycles, 68.7\%) [54], activated carbon// hetero-Ni-Co-S asymmetric device (5000 cycles, 86\%) [55] and $\mathrm{Co}_{9} \mathrm{~S}_{8} / 3 \mathrm{D}$ graphene//rGO hydrogel (6000 cycles, 86\%) [56]. Figures 8 h show the Nyquist plots of the $\mathrm{CoMoS}_{4} / / \mathrm{rGO}$ hybrid supercapacitor. The charge transfer resistance (the radius of the high frequency loop) is about $1.1 \Omega$, reflecting a low charge transfer resistance [57]. Moreover, the internal resistance (the real axis intercept) is $1.41 \Omega$, indicating the internal resistance [58]. In addition, the straight line is nearly perpendicular to the real axis, demonstrating low Warburg resistance, which will promote the diffusion of electrolytes into the electrode material and lead to a facile and reversible Faradaic redox. 

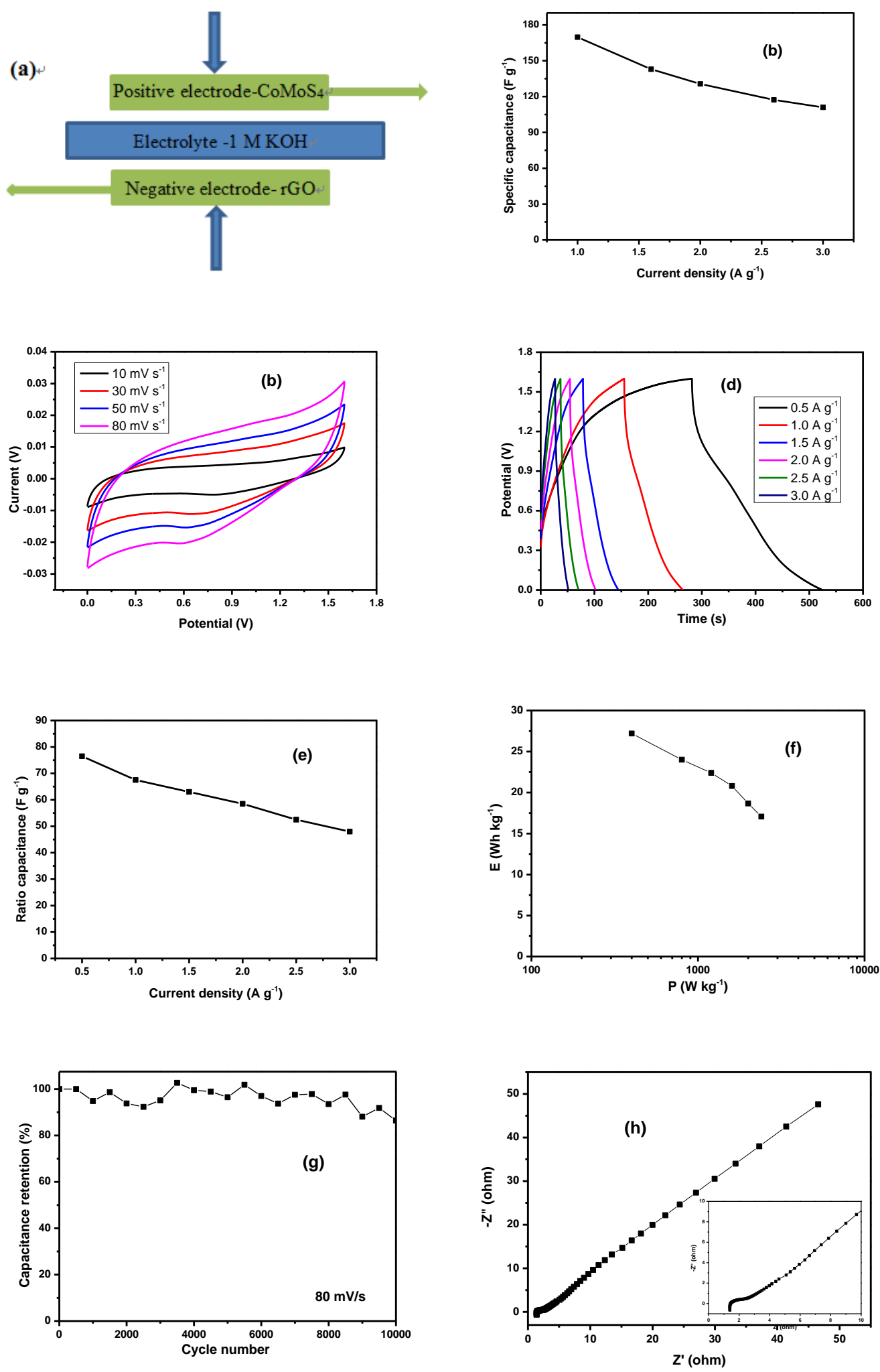

Figure 7. Schematic image of the $\mathrm{CoMoS}_{4} / / \mathrm{rGO}$ hybrid supercapacitor (a); specific capacitances of rGO (b); CV (c), GCD curves (d), ratio capacitances (e), Ragone plots (f), capacitance retention after 10000 cycles at $80 \mathrm{mV} \mathrm{s}^{-1}$ (g) and Nyquist plots (h) for 
the $\mathrm{CoMoS}_{4} / / \mathrm{rGO}$ hybrid supercapacitor

\section{Conclusions}

The amorphous $\mathrm{CoMoS}_{4}$ was prepared by a simple precipitation method. The $\mathrm{CoMoS}_{4}$ was used as the electrode material of supercapacitors for the first time and it exhibited the good electrochemical performance. The electrochemical behavior parameters of the $\mathrm{CoMoS}_{4}$ sample were studied by a three-electrode system. The ratio capacitance of $\mathrm{CoMoS}_{4}$ can reach $661 \mathrm{~F} \mathrm{~g}^{-1}$ at a current density of $1 \mathrm{~A} \mathrm{~g}^{-1}$. In order to determine the actual properties, the $\mathrm{CoMoS}_{4}$ symmetric device was constructed and showed the ratio capacitance of $142 \mathrm{~F} \mathrm{~g}^{-1}$ at $2 \mathrm{~A} \mathrm{~g}^{-1}$. Based on the good performances of $\mathrm{CoMoS}_{4}$, the $\mathrm{CoMoS}_{4} / / \mathrm{rGO}$ hybrid supercapacitor was constituted using $\mathrm{CoMoS}_{4}$ and rGO. The device exhibits good supercapacitive performances: the ratio capacitance is $77 \mathrm{~F} \mathrm{~g}^{-1}$ at $0.5 \mathrm{~A} \mathrm{~g}^{-1}$; the energy density can reach $27.2 \mathrm{Wh} \mathrm{kg}^{-1}$ at 400 $\mathrm{W} \mathrm{kg}^{-1}$, which retains $17 \mathrm{Wh} \mathrm{kg}^{-1}$ at $2400 \mathrm{~W} \mathrm{~kg}^{-1}$; capacitance retention is about $86 \%$ after 10000 cycles; low internal and Warburg resistances.

\section{Acknowledgements}

This work was financially supported by the National Science Foundation of China (21074089, 21276181).

\section{References}

[1] H.Y. Quan, B.C. Cheng, Y.H. Xiao, S.J. Lei, One-pot synthesis of alpha- $\mathrm{Fe}_{2} \mathrm{O}_{3}$ 
nanoplates-reduced graphene oxide composites for supercapacitor application, Chemical Engineering Journal 286 (2016) 165-173

[2] Z.B. Wu, X.L. Pu, X.B. Ji, Y.R. Zhu, M.J. Jing, Q.Y. Chen, F.P. Jiao, High energy density asymmetric supercapacitors from mesoporous $\mathrm{NiCo}_{2} \mathrm{~S}_{4}$ nanosheets, Electrochimica Acta 174 (2015) 238-245

[3] X.Y. Xu, J.P. Gao, G.B. Huang, H.X. Qiu, Z.Y. Wang, J.Z. Wu, Z. Pan, F.B. Xing, Fabrication of $\mathrm{CoWO}_{4} @ \mathrm{NiWO}_{4}$ nanocomposites with good supercapacitve performances, Electrochimica Acta 174 (2015) 837-845

[4] J.R. Miller, P. Simon, Materials science-Electrochemical capacitors for energy management, Science 321 (2008) 651-652

[5] Y.Z. Zhang, Y. Wang, T. Cheng, W.Y. Lai, H. Pang, W. Huang, Flexible supercapacitors based on paper substrates: a new paradigm for low-cost energy storage, Chem. Soc. Rev. 44 (2015) 5181-5199

[6] T. Brezesinski, J. Wang, S.H. Tolbert, B. Dunn, Ordered mesoporous $\alpha-\mathrm{MoO}_{3}$ with iso-oriented nanocrystalline walls for thin-film pseudocapacitors, Nature Materials 9 (2010) 146-151

[7] H.B. Wu, H. Pang, X.W. Lou, Facile synthesis of mesoporous $\mathrm{Ni}_{0.3} \mathrm{Co}_{2.7} \mathrm{O}_{4}$ hierarchical structures for high-performance supercapacitors, Energy \& Environmental Science 6 (2013) 3619-3626

[8] M.M. Yao, Z.H. Hu, Z.J. Xu, Y.F. Liu, P.P. Liu, Q. Zhang, Template synthesis and characterization of nanostructured hierarchical mesoporous ribbon-like $\mathrm{NiO}$ as high performance electrode material for supercapacitor, Electrochemica Acta 158 (2015) 
96-104

[9] W. Huang, H.H. Zhong, D.Q. Li, P.G. Tang, Y.J. Feng, Reduced graphene oxide supported $\mathrm{CoO} / \mathrm{MnO}_{2}$ electrocatalysts from layered double hydroxides for oxygen reduction reaction, Electrochemical Acta 173 (2015) 575-580

[10] X.H. Su, L. Yu, G. Cheng, H.H. Zhang, M. Sun, X.F. Zhang, High-performance alpha- $\mathrm{MnO}_{2}$ nanowire electrode for supercapacitors, Applied Energy 153 (2015) 94-100

[11] Q. Mahmood, H.J. Yun, W.S. Kim, H.S. Park, Highly uniform deposition of $\mathrm{MoO}_{3}$ nanodots on multiwalled carbon nanotubes for improved performance of supercapacitors, Journal of Power Sources 235 (2013) 187-192

[12] X. Lang, A. Hirata, T. Fujita, M. Chen, Nanoporous metal/oxide hybrid electrodes for electrochemical supercapacitors, Nature Nanotechnology 6 (2011) $232-236$

[13] J. Feng, X. Sun, C. Wu, L. Peng, C. Lin, S. Hu, J. Yang, Y. Xie, Metallic few-layered $\mathrm{VS}_{2}$ ultrathin nanosheets: high two-dimensional conductivity for in-plane supercapacitors, Journal of the American Chemical Society 133 (2011) 17832-17838

[14] X.Y. Yan, X.L. Tong, L. Ma, Y.M. Tian, Y.S. Cai, C.W. Gong, M.G. Zhang, L.P. Liang, Synthesis of porous NiS nanoflake arrays by ion exchange reaction from $\mathrm{NiO}$ and their high performance supercapacitor properties, Materials Letters 124 (2014) $133-136$

[15] W.D. Yu, W.R. Lin, X.F. Shao, Z.X. Hu, R.C. Li, D.S. Yuan, High performance supercapacitor based on $\mathrm{Ni}_{3} \mathrm{~S}_{2} /$ carbon nanofibers and carbon nanofibers electrodes 
derived from bacterial cellulose, Journal of Power Sources 272 (2014) 137-143

[16] J.H. Shi, X.C. Li, G.H. He, L. Zhang, M. Li, Electrodeposition of high-capacitance 3D CoS/graphene nanosheets on nickel foam for high-performance aqueous asymmetric supercapacitors, Journal of Materials Chemistry A 3 (2015) 20619-20626

[17] H.J. Tang, J.Y. Wang, H.J. Yin, H.J. Zhao, D. Wang, Z.Y. Tang, Growth of polypyrrole ultrathin films on $\mathrm{MoS}_{2}$ monolayers as high-performance supercapacitor electrodes, Advanced Materials 27 (2015) 1117-1123

[18] T. Kokubu, Y. Oaki, E. Hosono, H.S. Zhou, H. Imai, Biomimetic solid-solution precursors of metal carbonate for nanostructured metal oxides: $\mathrm{MnO} / \mathrm{Co}$ and $\mathrm{MnO}-\mathrm{CoO}$ nanostructures and their electrochemical properties, Advanced Functional Materials 21 (2011) 3673-3680

[19] X.J. Zheng, J.H. Guo, Y.T. Shi, F.Q. Xiong, W.H. Zhang, T.L. Ma, C. Li, Low-cost and high-performance $\mathrm{CoMoS}_{4}$ and $\mathrm{NiMoS}_{4}$ counter electrodes for dye-sensitized solar cells, Chemical Communication 49 (2013) 9645-9647

[20] G.H. Guo, Z.P. Song, C.J. Cong, K.L. Zhang, CoMoS 4 nanoflowers as anode for secondary lithium batteries, Journal of Nanoparticle Research 9 (2007) 653-656

[21] S. Dhibar, C.K. Das, Electrochemical performances of silver nanoparticles decorated polyaniline/graphene nanocomposite in different electrolytes, Journal of Alloys and Compounds 653 (2015) 486-497

[22] H. Pang, Y.Z. Zhang, Z. Run, W.Y. Lai, W. Huang, Amorphous nickel pyrophosphate microstructures for high-performance flexible solid-state 
electrochemical energy storage devices, Nano Energy 17 (2015) 339-347

[23] X.C. Li, L. Zhang, G.H. He, $\mathrm{Fe}_{3} \mathrm{O}_{4}$ doped double-shelled hollow carbon spheres with hierarchical pore network for durable high-performance supercapacitor, Carbon 99 (2016) 514-522

[24] J.H. Shi, X.C. Li, G.H. He, L. Zhang, M. Li, Electrodeposition of high-capacitance 3D CoS/graphene nanosheets on nickel foam for high-performance aqueous asymmetric supercapacitors, J. Mater. Chem. A 3 (2015) 20619-20626

[25] L.Y. Niu, Z.P. Li, Y. Xu, J.F. Sun, W. Hong, X.H. Liu, J.Q. Wang, S.R. Yang, Simple Synthesis of Amorphous $\mathrm{NiWO}_{4}$ Nanostructure and Its Application as a Novel Cathode Material for Asymmetric Supercapacitors, ACS Applied Materials \& Interfaces 5 (2013) 8044-8052

[26] H. Pang, Y.Z. Zhang, Z. Run, W.Y. Lai, W. Huang, Lamellar $\mathrm{K}_{2} \mathrm{Co}_{3}\left(\mathrm{P}_{2} \mathrm{O}_{7}\right)_{2} \cdot 2 \mathrm{H}_{2} \mathrm{O}$ nanocrystal whiskers: High-performance flexible all-solid-state asymmetric micro-supercapacitors via inkjet printing, Nano Energy 15 (2015) 303-312

[27] K. Polychronopoulou, C.D. Malliakas, J. He, M.G. Kanatzidis, Selective Surfaces: Quaternary $\mathrm{Co}(\mathrm{Ni}) \mathrm{MoS}$-Based Chalcogels with Divalent $\left(\mathrm{Pb}^{2+}, \mathrm{Cd}^{2+}, \mathrm{Pd}^{2+}\right)$ and Trivalent $\left(\mathrm{Cr}^{3+}, \mathrm{Bi}^{3+}\right)$ Metals for Gas Separation, Chemistry of Materials 24 (2012) $3380-3392$

[28] Y. Okamoto, K. Ochiai, M. Kawano, K. Kobayashi, T. Kubota, Effects of support on the activity of Co-Mo sulfide model catalysts, Applied Catalysis A: General 226 (2002) $115-127$

[29] W.D. Qiu, J.Q. Jiao, J. Xia, H.M. Zhong, L.P. Chen, A self-standing and flexible 
electrode of yolk-shell $\mathrm{CoS}_{2}$ spheres encapsulated with nitrogen-doped graphene for high-performance lithium-ion batteries, Chemistry-A European Journal 21 (2015) $4359-4367$

[30] S.R. Kadam, D.J. Late, R.P. Panmand, M.V. Kulkarni, L.K. Nikam, S.W. Gosavi, C.J. Park, B.B. Kale, Nanostructured 2D $\mathrm{MoS}_{2}$ honeycomb and hierarchical 3D $\mathrm{CdMoS}_{4}$ marigold nanoflowers for hydrogen production under solar light, Journal of Materials Chemistry A 3 (2015) 21233-21243

[31] Y.Q. Wu, X.Y. Chen, P.T. Ji, Q.Q. Zhou, Sol-gel approach for controllable synthesis and electrochemical properties of $\mathrm{NiCo}_{2} \mathrm{O}_{4}$ crystals as electrode materials for application in supercapacitors, Electrochimica Acta 56 (2011) 7517-7522

[32] S. Roldan, M. Granda, R. Menendez, R. Santamaria, C. Blanco, Supercapacitor modified with methylene blue as redox active electrolyte, Electrochimica Acta 83 (2012) 241-246

[33] J. Yan, Z. Fan, W. Sun, G. Ning, T. Wei, Q. Zhang, R. Zhang, L. Zhi, F. Wei, Advanced asymmetric supercapacitors based on $\mathrm{Ni}(\mathrm{OH})_{2} /$ graphene and porous graphene electrodes with high energy density, Advanced Functional Materials 22 (2012) 2632-2641

[34] C.Z. Yuan, J.Y. Li, L.R. Hou, L. Yang, L.F. Shen, X.G. Zhang, Facile template-free synthesis of ultralayered mesoporous nickel cobaltite nanowires towards high-performance electrochemical capacitors, Journal of Materials Chemistry 22 (2012) 16084-16090

[35] G. X. Wang, Q.Q. Tang, H. Bao, X.W. Li, G.C. Wang, Synthesis of hierarchical 
sulfonated graphene/ $\mathrm{MnO}_{2}$ /polyaniline ternary composite and its improved electrochemical performance, Journal of Power Sources 241 (2013) 231-238.

[36] J.G. Wang, Y. Yang, Z.H. Huang, F.Y. Kang, Rational synthesis of $\mathrm{MnO}_{2} /$ conducting polypyrrole@carbon nanofiber triaxial nano-cables for high-performance supercapacitors, Journal of Materials Chemistry 22 (2012) 16943-16949

[37] Y.F. Tang, T. Chen, S.X. Yu, Y.Q. Qiao, S.C. Mu, S.H. Zhang, Y.F. Zhao, L. Hou, W.W. Huang, F.M. Gao, A highly electronic conductive cobalt nickel sulphide dendrite/quasi-spherical nanocomposite for a supercapacitor electrode with ultrahigh areal specific capacitance, Journal of Power Sources 295 (2015) 314-322

[38] R. Ren, M.S. Faber, R. Dziedzic, Z.H. Wen, S. Jin, S. Mao, J.H. Chen, Metallic $\mathrm{CoS}_{2}$ nanowire electrodes for high cycling performance supercapacitors, Nanotechnology 26 (2015) 494001-494008

[39] P. Ilanchezhiyan, G.M. Kumar, T.W. Kang, Electrochemical studies of spherically clustered $\mathrm{MoS}_{2}$ nanostructures for electrode applications, Journal of Alloys and Compounds 634 (2015) 104-108

[40] L.N. Wang, Y. Ma, M. Yang, Y.X. Qi, Hierarchical hollow $\mathrm{MoS}_{2}$ nanospheres with enhanced electrochemical properties used as an Electrode in Supercapacitor, Electrochimica Acta 186 (2015) 391-396

[41] B.Q. Xie, Y. Chen, M.Y. Yu, T. Sun, L.H. Lu, T. Xie, Y. Zhang, Y.C. Wu, Hydrothermal synthesis of layered molybdenum sulfide/N-doped graphene hybrid with enhanced supercapacitor performance, Carbon 99 (2016) 35-42 
[42] R. Ramkumar, M. Minakshi, Fabrication of ultrathin $\mathrm{CoMoO}_{4}$ nanosheets modified with chitosan and their improved performance in energy storage device, Dalton Transactions 44 (2015) 6158-6168

[43] L.Q. Mai, F. Yang, Y.L. Zhao, X. Xu, L. Xu, Y.Z. Luo, Hierarchical $\mathrm{MnMoO}_{4} / \mathrm{CoMoO}_{4}$ heterostructured nanowires with enhanced supercapacitor performance, Nature Communications 2 (2011) 381

[44] L. Shen, L. Yu, H.B. Wu, X.Y. Yu, X. Zhang, X.W.D. Lou, Formation of nickel cobalt sulfide ball-in-ball hollow spheres with enhanced electrochemical pseudocapacitive properties, Nature Communication 6 (2015) 6694

[45] Y.H. Xue, L. Zhu, H. Chen, J. Qu, L.M. Dai, Multiscale patterning of graphene oxide and reduced graphene oxide for flexible supercapacitors, Carbon 92 (2015) $305-310$

[46] L.J. Ren, G.N. Zhang, Z. Yan, L.P. Kang, H. Xu, F. Shi, Z.B. Lei, Z.H. Liu, Three-Dimensional Tubular $\mathrm{MoS}_{2} / \mathrm{PANI}$ Hybrid Electrode for High Rate Performance Supercapacitor, ACS Appl. Mater. Interfaces 7 (2015) 28294-28302

[47] B. Senthilkumar, R.K. Selvan, D. Meyrick, M. Minakshi, Synthesis and characterization of manganese molybdate for symmetric capacitor applications, International Journal Electrochemical Science 10 (2015) 185-193

[48] R.T. Vinny, K. Chaitra, K. Venkatesh, N. Nagaraju, N. Kathyayini, An excellent cycle performance of asymmetric supercapacitor based on bristles like a- $\mathrm{MnO}_{2}$ nanoparticles grown on multiwalled carbon nanotubes, Journal of Power Sources 309 (2016) 212-220

[49] G.K. Veerasubramani, K. Krishnamoorthy, S.J. Kim, Electrochemical 
performance of an asymmetric supercapacitor based on graphene and cobalt molybdate electrodes, RSC Adv. 5 (2015) 16319

[50] S. Vikrant, G. Shubhra, S.R. Kishore, S. Gurmeet, Zinc oxide nanoring embedded lacey graphene nanoribbons in symmetric/asymmetric electrochemical capacitive energy storage, Nanoscale 7 (2015) 20642-20651

[51] A.D. Jagadale, G.Q. Guan, X.M. Li, X. Du, X.L. Ma, X.G. Hao, A. Abudula, Ultrathin nanoflakes of cobalt-manganese layered double hydroxide with high reversibility for asymmetric supercapacitor, Journal of Power Sources 306 (2016) $526-534$

[52] A. Shanmugavani, R.K. Selvan, Microwave assisted reflux synthesis of $\mathrm{NiCo}_{2} \mathrm{O}_{4} / \mathrm{NiO}$ composite: Fabrication of high performance asymmetric supercapacitor with $\mathrm{Fe}_{2} \mathrm{O}_{3}$, Eletrochimica Acta 189 (2016) 283-294

[53] Z.S. Wu, W.C. Ren, D.W. Wang, F. Li, B.L. Liu, H.M. Cheng, High-Energy $\mathrm{MnO}_{2}$ Nanowire/Graphene and Graphene Asymmetric Electrochemical Capacitors, ACS Nano 4 (2010) 5835-5842

[54] X.J. Ma, L.B. Kong, W.B. Zhang, M.C. Liu, Y.C. Luo, L. Kang, Design and synthesis of $3 \mathrm{D} \mathrm{Co}_{3} \mathrm{O}_{4} @ \mathrm{MMoO}_{4}(\mathrm{M}=\mathrm{Ni}, \mathrm{Co})$ nanocomposites as high-performance supercapacitor electrodes, Electrochimica Acta 130 (2014) 660-669

[55] H. Hua, S.J. Liu, Z.Y. Chen, R.Q. Bao, Y.Y. Shi, L.R. Hou, G. Pang, K.N. Hui, X.G. Zhang, C.Z. Yuan, Self-sacrifice Template Formation of Hollow Hetero- $\mathrm{Ni}_{7} \mathrm{~S}_{6} / \mathrm{Co}_{3} \mathrm{~S}_{4}$ Nanoboxes with Intriguing Pseudo-capacitance for High-performance Electrochemical Capacitors, Scientific Reports 6 (2016) 20973

[56] T.W. Lin, C.S. Dai, T.T. Tasi, S.W. Chou, J.Y. Lin, H.H. Shen, High-performance asymmetric supercapacitor based on $\mathrm{Co}_{9} \mathrm{~S}_{8} / 3 \mathrm{D}$ graphene composite and graphene hydrogel, Chemical Engineering Journal 279 (2015) 241-249 
[57] X.T. Zheng, Y.L. Ye, Q. Yang, B.Y. Geng, X.J. Zhang, Ultrafine nickel-copper carbonate hydroxide hierarchical nanowire networks for high-performance supercapacitor electrodes, Chemical Engineering Journal 290 (2016) 353-360 [58] F.Q. Liu, B.L. Yi, D.M. Xing, J.R. Yu, Z.J. Hou, Y.Z. Fu, Development of novel self-humidifying composite membranes for fuel cells, Journal of Power Sources 124 (2003) 81-89 